\title{
Erratum to: Structural analysis of the complex between calmodulin and full-length myelin basic protein, an intrinsically disordered molecule
}

Viivi Majava - Chaozhan Wang • Matti Myllykoski - Salla M. Kangas •

Sung Ung Kang • Nobuhiro Hayashi • Peter Baumgärtel • Anthony M. Heape •

Gert Lubec $\cdot$ Petri Kursula

Published online: 4 May 2010

(C) Springer-Verlag 2010

Erratum to: Amino Acids

DOI 10.1007/s00726-009-0364-2

Figure 5a, b: Unfortunately the figure was reproduced incorrectly.

This is the correct figure containing both (a) and (b) panels. In both of these, the units on the $y$-axis should be "deg" instead of "mdeg". The authors apologize for this mistake.

The online version of the original article can be found under doi:10.1007/s00726-009-0364-2.

V. Majava · C. Wang · M. Myllykoski · P. Kursula ( $ه)$ Department of Biochemistry, University of Oulu, PO Box 3000, 90014 Oulu, Finland e-mail: petri.kursula@oulu.fi

S. M. Kangas - A. M. Heape Department of Anatomy and Cell Biology,

Institute of Biomedicine, University of Oulu, Oulu, Finland

S. U. Kang · G. Lubec

Department of Pediatrics, Medical University of Vienna,

Vienna, Austria

N. Hayashi

Department of Life Science, Tokyo Institute of Technology,

Tokyo, Japan

P. Baumgärtel

Department of Physical Biochemistry, University of Potsdam,

Potsdam, Germany

P. Baumgärtel

Helmholtz-Zentrum Berlin, BESSY II, Berlin, Germany 
Fig. 5

(a)

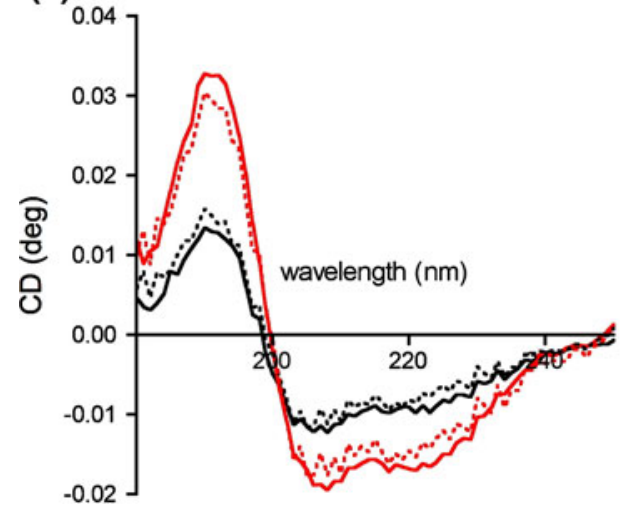

(b)

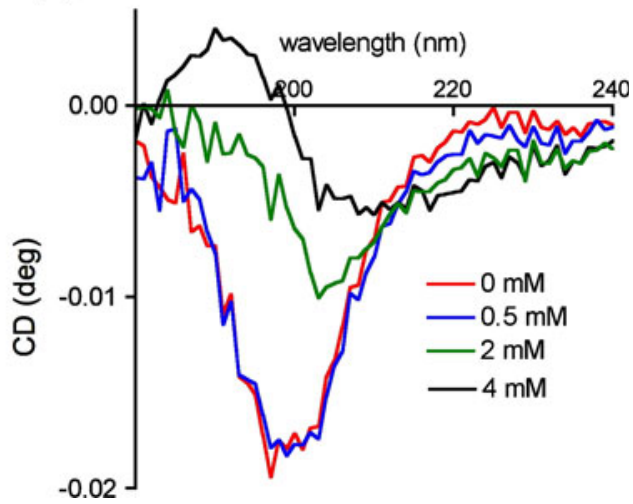

